\title{
Preparation and Characterization of Bioplastic from Sorghum Husk
}

\author{
Hannatu Abubakar Sani ${ }^{*}$, Abubakar Umar Birnin Yauri, Aliyu Muhammad, Yakubu Yahayya, \\ Mujahid Salau
}

Department Pure and Applied Chemistry, Faculty of Physical Science, Kebbi State University of Science and Technology Aleiro, Abuja, Nigeria

\section{Email address:}

hannatuabubakakar@gmail.com (H. A. Sani), abubkumar@gmail.com (A. U. B. Yauri), amnakowa@yahoo.com (A. Muhammad), yalmo72@gmail.com (Y. Yahayya), salaumujahid@gmail.com (M. Salau)

${ }^{*}$ Corresponding author

\section{To cite this article:}

Hannatu Abubakar Sani, Abubakar Umar Birnin Yauri, Aliyu Muhammad, Yakubu Yahayya, Mujahid Salau. Preparation and Characterization of Bioplastic from Sorghum Husk. American Journal of Polymer Science and Technology. Vol. 6, No. 2, 2020, pp. 14-20.

doi: $10.11648 /$ j.ajpst.20200602.12

Received: July 31, 2020; Accepted: August 18, 2020; Published: September 10, 2020

\begin{abstract}
The increase in global population and advances in technology have made plastic materials to have wide applications in every aspect of life. However, the non-biodegradability of these petrochemical-based materials, and their increasing accumulation in the environment has been a threat to the planet and has been a source of environmental concerns and hence, the driving force in the search for 'green' alternatives for which agricultural waste remains the front liner. Sorghum husk, an agricultural waste with potentials as raw material in production of bioplastic was used in this research to prepared bioplastic using sulphuric acid catalyzed acetylation process. The prepared bioplastic were characterized by X-ray diffraction and FT-IR. The FTIR spectra of the product displayed the presence of $\mathrm{OH}, \mathrm{C}-\mathrm{H}, \mathrm{C}=\mathrm{O}$ and $\mathrm{C}-\mathrm{O}$ absorption peaks which confirmed the formation of bioplastic. The new bioplastic obtained was biodegradable and was affected by acid, salt and alkali to a lesser extent, and this indicated that the produced bioplastic were much closed or has the same chemical resistance test with traditional plastic hence the prepared bioplastic can replaced the traditional plastic. Therefore, this revealed the new bioplastics with better environmental and sustainable properties can be produced from agricultural waste which may have application in many industries.
\end{abstract}

Keywords: Biodegradable, Bioplastic, Traditional Plastic

\section{Introduction}

The global population increase and advances in technology have made plastic materials to have wide applications in every aspect of life. However the non-biodegradability of these petrochemical-based materials, and their increasing accumulation in the environment has been a threat to the planet and has been a source of environmental concerns and hence, the driving force in the search for 'green' alternatives for which agricultural waste remains the front liner [1].

The term bioplastic refers to either the bio-based origin of a plastic or to the biodegradable character of a plastic [2]. Bio-based product is a product wholly or partly derived from biomass. Biomass is material of biological origin, excluding material embedded in geological formations and/or fossilized.
Examples are paper and wood [3].

Biodegradability depends strongly on the environmental conditions: temperature, presence of microorganisms, presence of oxygen and water [4]. Biodegradable plastic offer a lot of advantages such as reducing greenhouse gas emission, increased soil fertility, low accumulation of bulky plastic materials in the environment and reduction in the cost of waste management [5]. Biodegradable materials already play an important role in the field of packaging, agriculture, medicine, gastronomy consumer electronics automotive and other areas $[6,7]$.

The most favored end-of-life disposal options for these materials are domestic and municipal composition instead of landfill which is the worst disposal option [8]. Therefore, biodegradable polymers can make significant contributions to material recovery, reduction of landfill and utilization of renewable resources [9]. 
Agricultural waste are among the causes of environmental pollution. Their conversion into useful products may solve the problem the cause [10]. These waste which include cereal, straw, leaves, corncobs are highly underutilized in Nigeria [11].

Sorghum husk is one of the agricultural residues produced as by-product during the processing of the grains. Traditionally grains are prepared by pounding to remove the husk. The husk is left on the farm site after harvest. This resource is costless and zero competition in terms of consumption and usage in Nigeria [12].

The aim of this research, was to use lower cost agricultural waste such as sorghum husk for the production of bioplastic, which can help reducing environmental problem that are caused by traditional plastic (petroleum based plastic). Bioplastic Production is one of the methods to control and minimize petroleum based plastic usage. This research will helps in promoting a way of synthesizing biopolymer using waste from Agricultural activities. It could assist in lowering the production cost that restrains a wide synthesis of bioplastic.

\section{Experimental}

\subsection{Material and Chemicals}

$500 \mathrm{~g}$ of dry sample of sorghum husk was collected randomly from Aleiro Area of kebbi state, Nigeria. The husk was washed with water and bleached with $120 \mathrm{ml}$ of household bleaching agent (5\% NaOCI and 5\% $\mathrm{NaOH})$, thoroughly washed so as to removed dusts and color. The husk was dried in a ventilated room away from dust and direct sunlight. The dried husk was ground to fine powder using mortar and pestle. The ground samples was then transferred into separate plastic bags, tied, labeled and stored in a dry place for further work. Bioplastic resistance test was carried out using acids, alkalis and Salts. Glacial acetic acid, acetic anhydride, Sulfuric acid, Sodium hydroxide, Sodium chloride Salt and Lead acetate Salt were all standard and were of analytical grade. Sulfuric acid was used as a catalyst and also for the acid resistance test. Acetone was used as Solvent, glycerol was used as a plasticizer.

\subsection{Preparation of Bioplastic}

$35 \mathrm{~g}$ powder sample of sorghum husk was used. Acetic anhydride $(100 \mathrm{ml})$, glacial acetic acid $(100 \mathrm{ml})$ and sulfuric acid $(10 \mathrm{ml})$ were mixed and the mixture was cooled in refrigerator $\left(7^{\circ} \mathrm{C}\right)$. Sorghum husk was added slowly to the previous mixture with agitation to bring about acetylation process. The resulting viscous fluid was centrifuged in order to separate the final product. Plasticizer Glycerol was added as $25 \%$ by volume of the viscous liquid with agitation. The final product form was dried in an oven at $60^{\circ} \mathrm{C}$, until a constant weight is obtain in order to get the product ready for use. The product is diluted with acetone to bring it in to the form of a viscous fluid which could be poured in a mold or on a smooth surface for shaping [13]. The product was mold in to circular shape as figure 1 below.

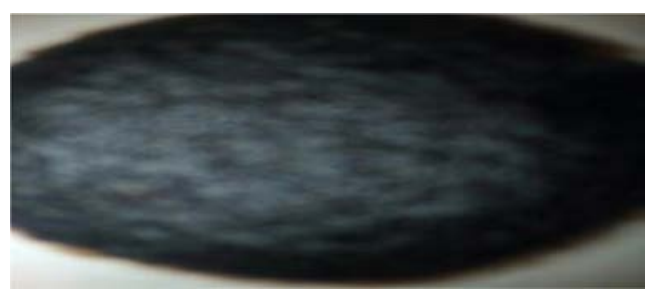

Figure 1. Sorghum husk bioplastic.

\subsection{Biodegradability Tests}

\subsubsection{Biodegradation by Composting}

Biodegradable composting method was employed to test the biodegrability of the prepared plastic [14]. $2 \mathrm{~g}$ of prepared plastic was vacuum dried for $24 \mathrm{~h}$ at $45^{\circ} \mathrm{C}$ and buried in to the municipal solid waste mixture (for 15 days) for possible biodegradation. The content was kept in an oven at $55^{\circ} \mathrm{C}$, at which the maximum growth of thermophiles microorganisms was occurred. The buried bioplastic sample was weight after three days for a period of 15 days in order to determine the percentage of weight loss.

\subsubsection{Bench - Scale Simulated Composting}

In this test, the compost was consisted of $50 \%(\mathrm{w} / \mathrm{w})$ cow manure and garden soil. Three bioplastic samples each of $2 \mathrm{~g}$ were used for this analysis and the samples were buried in a separate reaction vessel container consisting of inoculums $(50 \% \quad(\mathrm{w} / \mathrm{w})$ cow manure and garden soil). For characterization, the bioplastic samples were removed from the compost at three day intervals in order to calculate the weight loss. The average weight loss of the three bioplastic samples was observed and recorded. Also, the temperature of the compost was measured and recorded daily. Percentage weight loss for the materials were measured according to Khan, et al. 2006, by the following equation:

$$
\% \text { Weight loss }=\frac{\mathrm{W} 1-\mathrm{W} 2}{\mathrm{~W} 1} \times 100
$$

Where:

W1 and W2 were the Samples weight before and after treatment.

\subsection{Chemical Tests}

\subsubsection{Effect of Acids}

$2 \mathrm{~g}$ of the prepared plastic was weight and, then put into Sulfuric acid with concentration of $50 \%$. The dried samples was weight periodically for 4 days. The percentage weight loss was observed after each time period.

\subsubsection{Effect of Alkalis}

$2 \mathrm{~g}$ of the prepare plastic was put into alkali solution (sodium hydroxide) with concentrations $(50 \%)$. The percentage weight loss was calculated daily for a period of ten days.

\subsubsection{Effect of Salts}

$2 \mathrm{~g}$ of the prepared plastic were mixed with different solid salts in different container, and left for 5 days, with periodic weighing every day, and its resistance to the action of salts 
(The sodium chloride, trisodium orthophosphate and lead acetate) was observed.

\subsection{Characterization of the Produced Bioplastic}

\subsubsection{X-ray Diffraction (XRD)}

The crystal structure of the prepared plastic was analyze using X-ray diffract meter instrument PanAnalitical Empyrean between $5^{\circ}$ and $80^{\circ}$ at a scanning rate of $2 \% \mathrm{~min}$ [15].

\subsubsection{Fourier Transforms Infrared (FTIR)}

The functional group were determined by FTIR to confirm the structure of prepared plastic by using Shimadzu via the $\mathrm{KBr}$ pressed disc [16].

\subsection{Statistical Analysis}

The mean value for some of the parameter was calculated. Calculators was used were necessary. For determining the significant of inter-group differences, each parameter was analyze separately. A software called Origin was used in making graphs.

\section{Results and Discussion}

\subsection{Preparation of Bioplastic}

The experimental results showed that the yield of bioplastic obtained from Sorghum husk was $19.0 \mathrm{~g}$ which is equal to $184.2 \%$. In this study. The colour of the viscous fluid obtain (bioplastics) from the husk is black which shows dark red when touch or pour in hand or on a surface. Therefore, the acetylation process, used in this work, produced a dark brown residue with bad smell which indicate the formation of bioplastic.

\subsection{Results of Biodegradability Tests}

Figure 2, below show the results of biodegradation from composting and bench-scale simulated composting tests, for bioplastics sample from Sorghum husk. The bioplastic sample from the figure 2 below shows that, in the case of biodegradation tests from composting (represented by graphic $\mathrm{a}$ in figure 2 below), $2 \mathrm{~g}$ of bioplastic sample from Sorghum husk lost $31.5 \%$ of its weight after the first three days and then, the percentage of weight loss continued to increase over time until it reached $85.0 \%$ after 15 days. The results of the benchscale simulated composting tests (represented by graphic $b$ in figure 2 below) show that, $2 \mathrm{~g}$ of a bioplastic sample from Sorghum husk lost $45.1 \%$ of its weight after the first three days. And the percentage of weight loss continued to decrease over time until it reached $13.9 \%$ after 15 days (indicated by $\mathrm{x}$-axis from figure 2 below). The variation in the temperature of the compost (represented by graphic $\mathrm{c}$ in figure 2 below) which result in an increase in weight loss indicated that, the bioplastic produced from Sorghum husk is biodegradable by the thermophiles microorganisms. The bioplastic samples produced from husk, has a smooth and slight increase in the rate of biodegradation, hence it may likely be as a result of minor variations in the chemical structure of the Bioplastic produced from the husks.

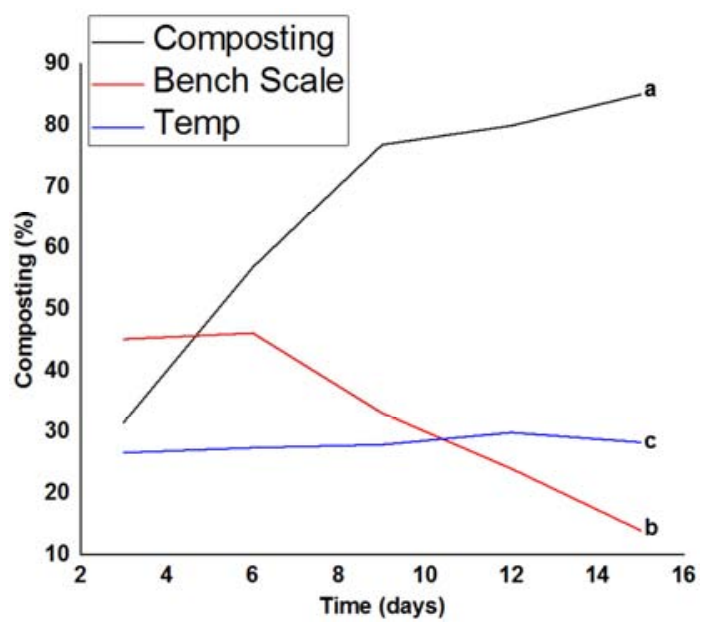

Figure 2. Biodegradability test by composting and bench-scale of Bioplastic sample produced from Sorghum husk.

\subsection{Chemical Tests}

\subsubsection{Result of the Effect of Acid on the Bioplastic Produced}

The figure 3 and table 1 below shows the results of the effects of concentrated sulfuric acid $(98 \%)$ on bioplastic sample produced from Sorghum husk. The weight loss of bioplastic produced has a slight increases. However the bioplastic produced shows a lower \% weight loss (7.4\%). As observed on the fourth days from figure 3 and table 1 below, the $\%$ weight loss of Bioplastic from Sorghum husk was $15.2 \%$, this indicated that the bioplastic produced from the Sorghum husks has a very good acid resistance. In general the bioplastic produced from Sorghum husks are affected to some extent by acid $14.8 \%$ after 2 days, and $14.8 \%$ on the third days, compared to commercial polystyrene and polypropylene from table 1 below, that was not affected by acid under the same condition and time (for 4 days).

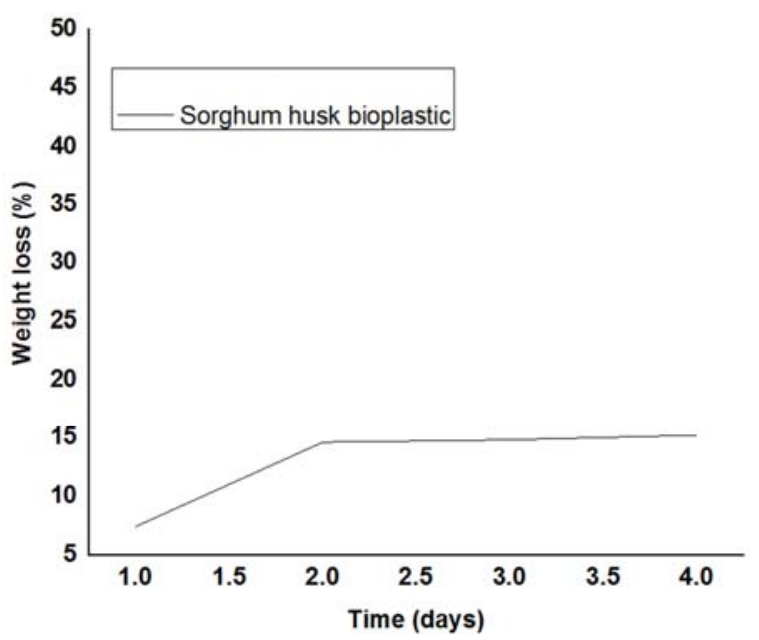

Figure 3. Effect of 50\% concentrations of sulfuric acid on weight loss of Bioplastic Sample produced from Sorghum husk. 


\subsubsection{Result of the Effect of Alkalis on Bioplastics Produce}

The figure 4 below illustrate the results from the effects of Sodium hydroxide on bioplastic produced from Sorghum husk. The \% weight loss of bioplastic produced from Sorghum husks increased over time. A maximum weight loss of $76.0 \%$ was observed for bioplastic produced from Sorghum husk after 10 days treatment. From the first 4 days, a maximum of $38.5 \%$ percentage weight loss was observed from bioplastic produced from Sorghum husk, compared to commercial polystyrene and polypropylene which gave $10 \%$ and $30 \%$ weight loss under the same condition after 4 days respectively. The comparison test result from table 1 below shows that, the resistance of the prepared bioplastic from Sorghum husk to alkalis was slightly close to the resistance values of polypropylene but higher than that of polystyrene. However the Bioplastic produced from sorghum husk had a poor alkalis resistance when compared to commercial Bioplastic which have a good resistance factor $(=3)$ for strong alkalis [17].

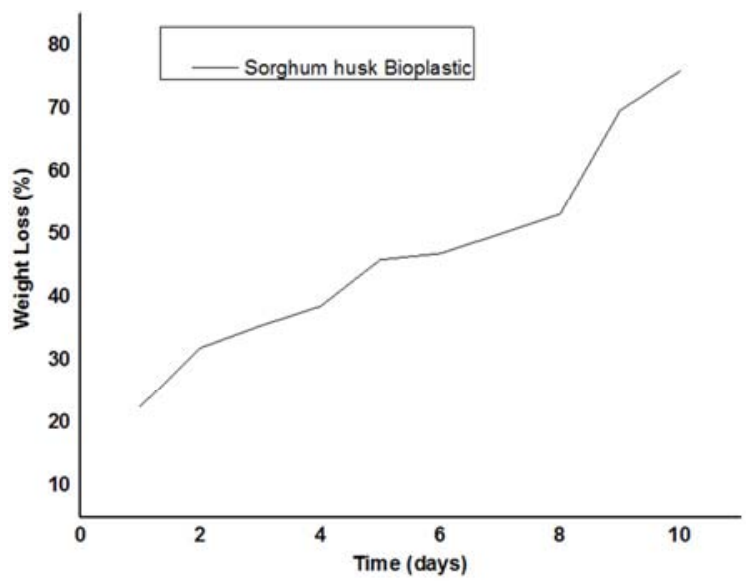

Figure 4. Effect of 50\% concentration of Sodium hydroxide on weight loss of Bioplastic Sample produced from Sorghum husk.

\subsubsection{Effect of Salts on the Bioplastic}

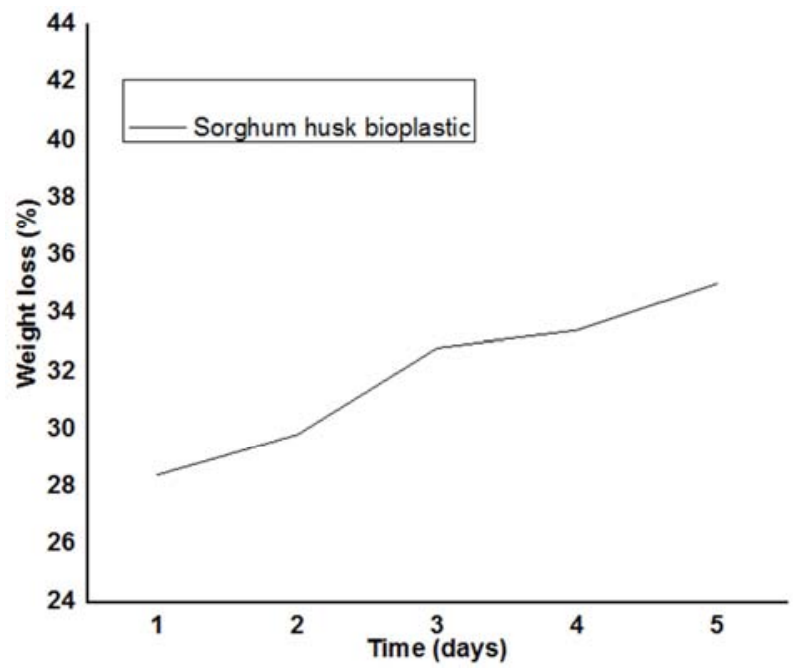

Figure 5. Effect of Trisodium orthoposphate Salt on weight loss of Bioplastic Sample produced from Sorghum husk.

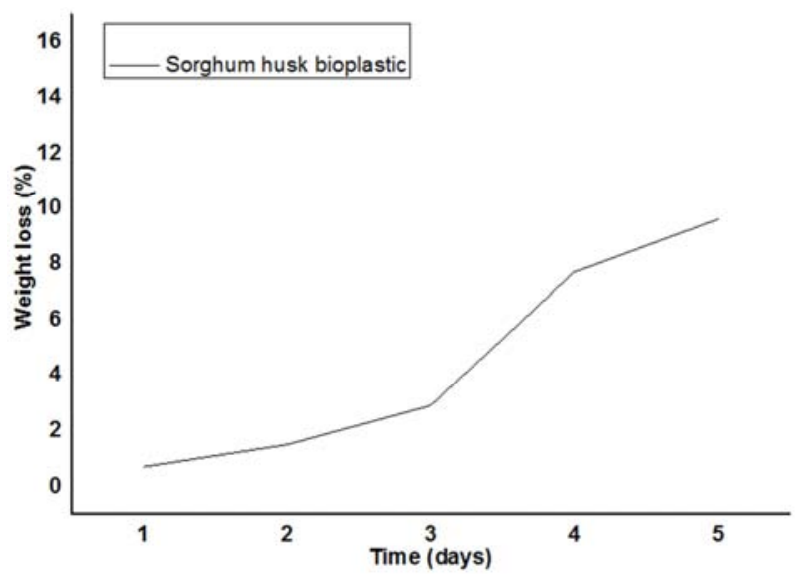

Figure 6. Effect of Sodium Chloride Salt and on weight loss of Bioplastic Sample produced from Sorghum husk.

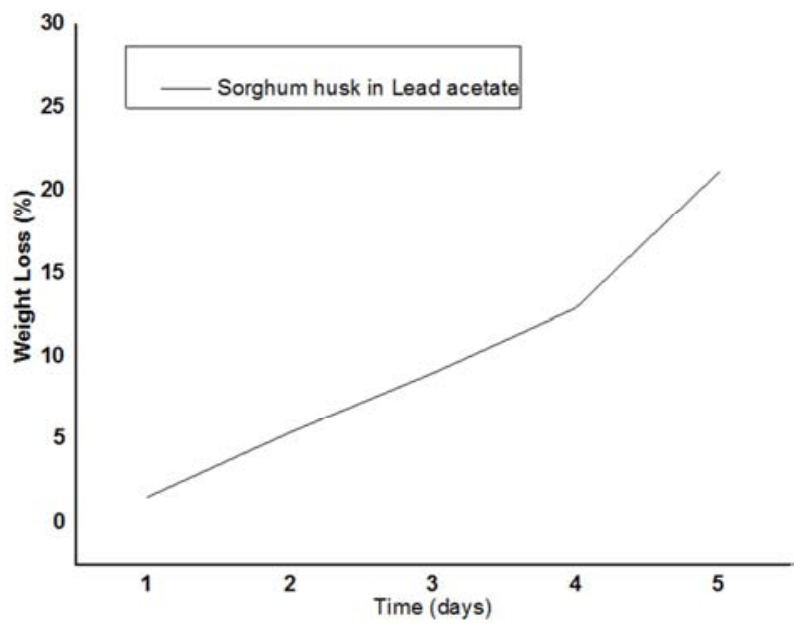

Figure 7. Effect of Lead acetate Salt on weight loss of Bioplastic Sample produced from Sorghum husk.

The result in figures 5, 6, and 7 illustrate the effect of Trisodium orthophosphate salt, Sodium chloride salt and lead acetate salt on the produced bioplastic. The test shows that the salts had minor effects on the produced bioplastic, where it shows a slight weight loss when mixed with those Salts for five days. The produced bioplastic can be used for manufacturing containers for salts and tools for plastic since salts has minor effect on the prepare bioplastic, hence it can resist the effect of the salt and it is consistence with the environmental resistance factors of the commercial bioplastic for sea water $(=5)$ [17].

\subsection{Result of X-ray Diffraction Analysis}

Figure 8 below shows the diffract gram of commercial cellulose acetate bioplastic (represented by diffract gram B), fresh sorghum husk (represented by diffract gram C) and prepared Sorghum husk bioplastic (presented by diffract gram A). The prepared Sorghum husk bioplastic (represented by diffract gram A) shows peaks around $2 \Theta=18^{\circ}, 2^{\circ \circ}, 22^{\circ}$, $25^{\circ}, 26.4^{\circ}, 49.9^{\circ}, 59.9^{\circ}, 68.2^{\circ}$, fresh Sorghum husk XRD pattern (represented by diffract gram $\mathrm{C}$ ) shows peaks around $2 \Theta=16.8^{\circ}, 2^{\circ} .8^{\circ}, 23^{\circ}, 26.4^{\circ}, 4^{\circ \circ}, 42^{\circ}, 49.9^{\circ}, 56^{\circ}, 59.9^{\circ}, 64.2^{\circ}$, 
$68.1^{\circ}$ and commercial cellulose acetate (represented by diffract gram B) shows peaks around $2 \theta=13^{\circ}, 16^{\circ}, 23^{\circ}, 25^{\circ}$, $28^{\circ}, 38^{\circ}, 51^{\circ}$. The cellulose acetate bioplastic shows it first two peaks around $13^{\circ}, 16^{\circ}$, the fresh Sorghum husk diffract gram (represented by diffract gram C) shows it first two peaks angle around $16.8^{\circ}$ and $19.8^{\circ}$, the prepared sorghum husk bioplastic diffract gram (presented by diffract gram A) shows it first two peaks around $18^{\circ}, 2^{\circ}$. The XRD patterns of normal Starch in the present of glycerol were about $16.8^{\circ}$ and $19.8^{\circ}$. [15]. Therefore angle around $16^{\circ}, 19^{\circ}$, indicated the peaks angle of Cellulose, but after the husks was mixed with the chemicals (Bioplastic formation), it shows that the peak angles shifted to about $18^{\circ}$ and $2^{\circ}$. When the prepared Sorghum husk bioplastic (presented by diffract gram A) was compared with commercial cellulose acetate (represented by diffract gram B), it was found that the only difference between them is change to upper angle as follow $\left[13^{\circ}\left(18^{\circ}\right)\right.$, $\left.16^{\circ}\left(2^{\circ}\right), 23^{\circ}\left(22^{\circ}\right), 25^{\circ}\left(26^{\circ}\right), 28^{\circ}\left(51^{\circ}\right), 38^{\circ}\left(6^{\circ}\right), 51^{\circ}\left(68^{\circ}\right)\right]$, hence comparison between the diffract gram of both bioplastic (Sorghum husk bioplastic and Commercial cellulose acetate bioplastic) from figure 8 below, indicated clearly that the prepared bioplastic was Cellulose acetate. The change to upper angle implies that the mixed constituent had an arranged structure. However, the strong crystalline characteristic was showed and the peaks angle of the bioplastic indicated that the additive have a well-arranged structure [18]. The produce diffract gram obtained resemble with the diffract gram obtained by $[19,2]$. The experimental works suggest the prepared Sorghum husk bioplastic to be cellulose acetate.

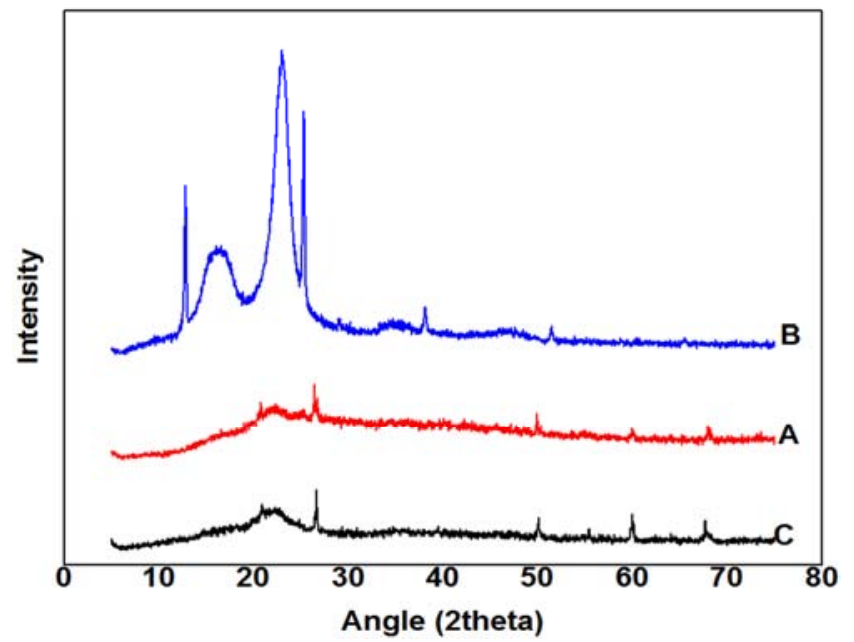

Figure 8. X-ray diffraction of Cellulose acetate, prepared Sorghum husk bioplastic and fresh Sorghum husk.

\subsection{Result of FTIR Spectra}

The analysis of FT-IR shows the distinguishing peaks from bioplastic. FT-IF has ability to measured functional groups in greater speed and greater sensitivity [21]. FT-IR used it indirect analytical method to study molecular structure 22 . Figure 9 below shows the characteristic peaks of fresh Sorghum husk (represented by (a) in figure 9 below), prepared bioplastic from sorghum husk (presented by graphic b) and commercial cellulose acetate bioplastic (represented by graphic $\mathrm{c}$ in figure 9 below). From the figure 9 below when comparing the characteristic peaks of the FTIR of the prepared bioplastic and Commercial cellulose acetate, it was found that there are the same, and when comparing the characteristic peaks of the FTIR of husks (a) and the produced bioplastic (b), it shows evidence of formation of new founctional group $\mathrm{C}=\mathrm{O}$. The observations of these characteristic peaks provide evidence of acetylation. In general the spectra of both bioplastics used from this study displayed the presence of four major absorption peaks which are $\mathrm{O}-\mathrm{H}, \mathrm{C}-\mathrm{H}, \mathrm{C}=\mathrm{O}$, and $\mathrm{C}-\mathrm{O}$. From this analysis, evidence from the formation of this four functional group indicate the production of bioplastic. Comparing the FTIR of the Produced bioplastic with the FTIR of commercial cellulose acetate and others review, qualify the production to be cellulose acetate.

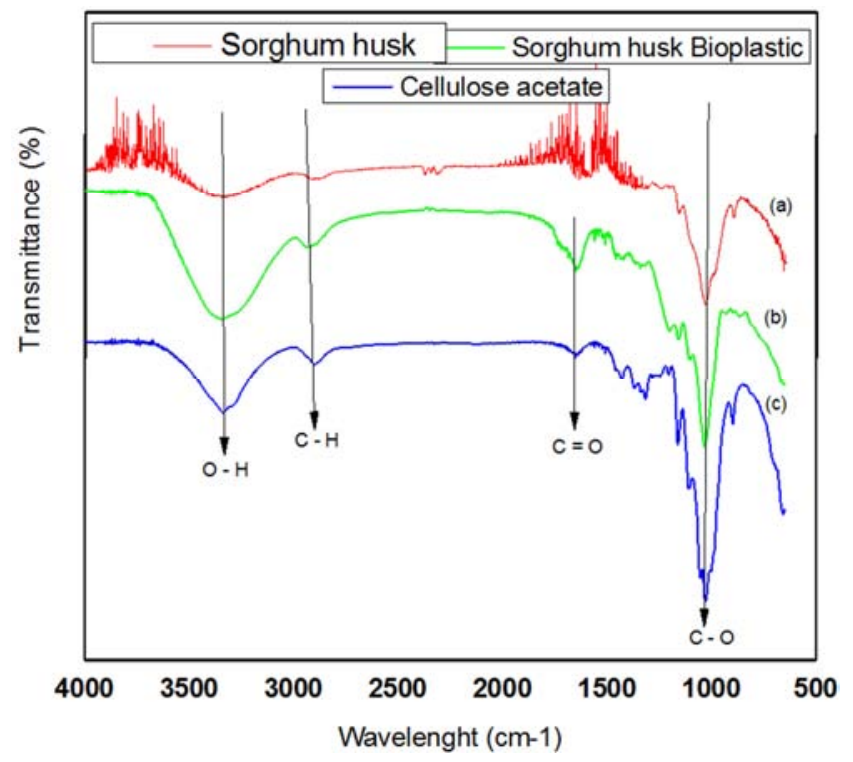

Figure 9. FTIR of Sorghum husk, Sorghum husk bioplastic and Cellulose acetate Bioplastic.

Table 1, Results of Chemical resistance test of Sorghum husk bioplastic.

\begin{tabular}{llllll}
\hline Bioplastic From & Chemical used & Initial QuantiTy of Sample (g) & Observation 1th day & $\mathbf{2}^{\text {nd }}$ day & $\mathbf{3}^{\text {th }}$ day \\
\hline Sorghum Husk & Sulfuric acid & 2.00 & 1.85 & 1.71 \\
\% Weight Losses & & & 7.40 & 1.70 \\
PolyStyrene & Sulfuric acid & 1.00 & 1.00 & 1.6 & 14.8 \\
Polyethylene & Sulfuric acid & 1.00 & 1.00 & 1.00 & 1.00 \\
polypropylene & Sulfuric acid & 1.00 & 1.00 & 1.00 & 1.00 \\
Sorghum Husk & NaOH Solution & 2.00 & 1.55 & 1.00 & 1.00 \\
\% Weight Losses & & & 22.5 & 1.36 & 1.29 \\
\hline
\end{tabular}




\begin{tabular}{|c|c|c|c|c|c|}
\hline Bioplastic From & Chemical used & Initial QuantiTy of Sample (g) & Observation 1th day & $2^{\text {nd }}$ day & $3^{\text {th }}$ day \\
\hline $\begin{array}{l}\text { Polystyrene } \\
\% \text { weight loss }\end{array}$ & $\mathrm{NaOH}$ & 1.00 & & & \\
\hline $\begin{array}{l}\text { Polypropyle } \\
\% \text { weight loss }\end{array}$ & $\mathrm{NaOH}$ & 1.00 & & & \\
\hline Polyethylene & $\mathrm{NaOH}$ & 1.00 & & & \\
\hline Sorghum Husk & $\mathrm{NaCl}$ Salt & 2.00 & 1.99 & 1.97 & 1.94 \\
\hline$\%$ Weight Losses & & & 0.7 & 1.5 & 2.9 \\
\hline $\begin{array}{l}\text { Sorghgum Husk } \\
\% \text { Weight Losses }\end{array}$ & Lead acetate Salt & 2.00 & $\begin{array}{l}1.971 \\
1.5\end{array}$ & $\begin{array}{l}1.89 \\
5.4\end{array}$ & $\begin{array}{l}1.82 \\
9.0\end{array}$ \\
\hline $\begin{array}{l}\text { Sorghum Husk } \\
\% \text { Weight Losses }\end{array}$ & TriSodiumorthoposphatee & 2.00 & $\begin{array}{l}1.432 \\
28.4\end{array}$ & $\begin{array}{l}1.41 \\
29.8\end{array}$ & $\begin{array}{l}1.35 \\
32.8\end{array}$ \\
\hline
\end{tabular}

Table 1, Continued.

\begin{tabular}{|c|c|c|c|c|c|c|c|}
\hline Bioplastic From & $4^{\text {th }}$ day & $5^{\text {th }}$ day & $6^{\text {th }}$ day & $7^{\text {th }}$ day & $8^{\text {th }}$ day & $9^{\text {th }}$ day & $10^{\text {th }}$ day \\
\hline Sorghum Husk & 1.69 & & & & & & \\
\hline \% Weight Losses & 15.2 & & & & & & \\
\hline PolyStyrene & 1.00 & & & & & & \\
\hline Polyethylene & 1.00 & & & & & & \\
\hline polypropylene & 1.00 & & & & & & \\
\hline Sorghum Husk & 1.23 & 1.08 & 1.06 & 1.0 & 0.94 & 0.61 & 0.48 \\
\hline$\%$ Weight Losses & 38.5 & 45.9 & 46.9 & 50 & 53.2 & 69.7 & 76.0 \\
\hline Polystyrene & 0.9 & & & & & & \\
\hline$\%$ weight loss & 10 & & & & & & \\
\hline Polypropyle & 0.80 & & & & & & \\
\hline$\%$ weight loss & 30 & & & & & & \\
\hline Polyethylene & 1.00 & & & & & & \\
\hline Sorghum Husk & 1.84 & 1.80 & & & & & \\
\hline$\%$ Weight Losses & 7.7 & 9.6 & & & & & \\
\hline Sorghgum Husk & 1.74 & 1.58 & & & & & \\
\hline$\%$ Weight Losses & 12.9 & 21.1 & & & & & \\
\hline Sorghum Husk & 1.33 & 1.30 & & & & & \\
\hline$\%$ Weight Losses & 33.4 & 35.0 & & & & & \\
\hline
\end{tabular}

\section{Conclusion}

The yield of bioplastic obtained from Sorghum husk was $19.0 \mathrm{~g}$ which is equal to $184.2 \%$. The observations of the characteristic peaks from FT-IR provide evidence of acetylation. From the FTIR analysis, evidence from the formation of the four functional group indicate the production of bioplastic. And observation from XRD analysis indicated clearly that the produced was Cellulose acetate. The change to upper angle in XRD implies that the mixed constituent had an arranged structure. The Quality of the bioplastic produced, been it biodegradable and Resistant to Chemical may makes it, deserving biomaterial for commercial development, e.g. materials for packaging salt containers. As observe from the study, this bioplastic may be able to have potential to replace or minimize the used of nonbiodegradable material and petroleum-based material for sustainable development.

\section{Acknowledgements}

We are thankful to the Tertiary education Trust fund (TETFUND) Nigeria for research finding and Department of Pure and Applied Chemistry KSUSTA for research facilities.

\section{References}

[1] Tokiwa, Y., Calabia, B. P., Ugwu, C. U. and S., and Aiba, S., (2009) Biodegradability of Plastics International journal of Molecular Sciences.

[2] Maulida, M Siagian, P Taarigan (2016). Production of Starch Based Bioplastic from Cassava Peel Reinforced with Microcrystalline Cellulose Avicel PH 101 using Sobitol as Plasticizer. Journal of Physic: Conference Series (2016) 012012. IOP Publishing doi: 10.1088/17426596/710/1/012012.

[3] Saharan, B, S., Ankita and Sharma, D (2012), Bioplastic-For Sustainable Development: A Review international Journal of Microbial Resource Technology, 1 (1): 11-23.

[4] Shibata, M; Oyamada, S, Kobayashi, S. I. Yaginoma, D. (2004) Mechanical properties and biodegradability of green composites based on biodegradable polyesters and lyocell fabric. J. Appl. Sci. 92, 3857-3863.

[5] Jain R, Tiwari A (2015). Biosynthesis of planet friendly bioplastic using renewable carbon source. J Environ. Health Sci. Eng. 13.

[6] Viviana. U., Pamela. V., Gonzlez. M., Seeger. M., 2014. (2014). Bacterial production of the biodegradable plastics polyhydroxyalkanoates. Int. J. Biol. Macromol. 70. 208-213. 
[7] D'souza, R. L., Unnikrishnan, Geetha (2018) Bioplastic A step towards sustainability international journal of current Trend in Science and Technology, 8 (5).

[8] Mose B R, Maranga S M (2011). A review on starch based nanocomposites for bioplastic materials. J Mol. Sci. Eng. 1 239-245.

[9] Vieira M G A, Silva M A. D, Santos L O D. Beppu M M (2011 Natural- based plasticizers and biopolymer firms: A review Eur. Polym. J. 47 254-263).

[10] Chandi, G. k., and sogi, D. S (2007). Functional properties of rice bran protein concentrate. Journal of food engineering, 79, 592-597. doi: 101016/j.jfoodeng.2006.02.2018.

[11] Latta, M., and Eskin, M. (1980). A simple and rapid method for phytate determination. Journal of agriculture food chemistry, 28, 1313-1315. doi: 10. 1021/jf60232a049.

[12] Abubakar, M. S. and Ahmad D. (2005) Pattern in Energy consumption in millet production in selected farm in Jigawa State. Aus. J. Aappl. Sci, 4 (4): 666-672.

[13] Nishino, T., Kotera, M., Suetsugu, M., Murakami, H., Urushihara, Y., (2011). Acetylation of plant cellulose fibre in supercritical carbondioxide. Polymer 52, 830-836.

[14] Khan, A., Bhattacharia, K., Kader A., and Bahari, K., (2006). Preparation and characterization of ultra violet (UV) radiation cured bio-degradable films of sago starch/PVA blend. Carbohydrate polymers, 63. Pp500-506.

[15] Heru S., Prihanto Tri H., Reza W., Poppy P., and Sukarni (2016), report on the stucture of bioplastic from cassava starch with nanoclay reinforcement Proceedings of the international mechanical engineering and engineering education conferences (impeach 2016) aip conf. proc. 1778, 030027-1030027-4; doi: 10.1063/1.4965761published by AIP publishing. 978-0-7354-1440-2/\$30.00. 0300271.

[16] Jayachandra Y., Vinay P., Sharanabasava G., Nagaraj B., Anand H., and Ashok S., (2016) biodegradable plastic production from fruit waste material and its sustainable use for green applications. International Journal of Pharmaceutical Research \& Allied Sciences, 5 (4): Pp56-66.

[17] Granta design limited lim, hwee ling 2014. Technology and engineering hand book of research on recent developments in material science cambridge, U. K. Retrieved December 10, 2013.

[18] Harkins, A. L, Duri, S, Kloth, L. C., Tran, C. D., 2014, Chitosan-Cellulose Composite for wound dressing material. Part 2. Antimicrobial activity. Blood absorption ability, and biocompatibility. J Biomed. Mater. Res. Part b Appl. Biomater. 102, 1199-1203.

[19] Mostafa, N. A., Farag A. A., Abo-dief, H. M., Tayeb, A. M. (2015) Production biodegradable plastic from agricultural wastes. Arabian Journal of Chemistry.

[20] Ritu (2017) Investication of Bioplastic Properties Developed From Acrylate Epoxidized Soybean Oil, through Ring Opening Polymerization Process. Journal of Chemical Engineering and Industrial Biotechnology V1 (2017) 29-41.

[21] Porras M S, Cubitto M A, Villar MA (2015). A new way of quantifying the production of poly (hydroxyalkanoate) s using FTIR. J Chem. Tech. Biotechnol.

[22] Pavia D L, Lampman G M, Kris G S (2001). Introduction to spectroscopy (Philadelphia: Thomson Brooks/Cole). P 23. 